
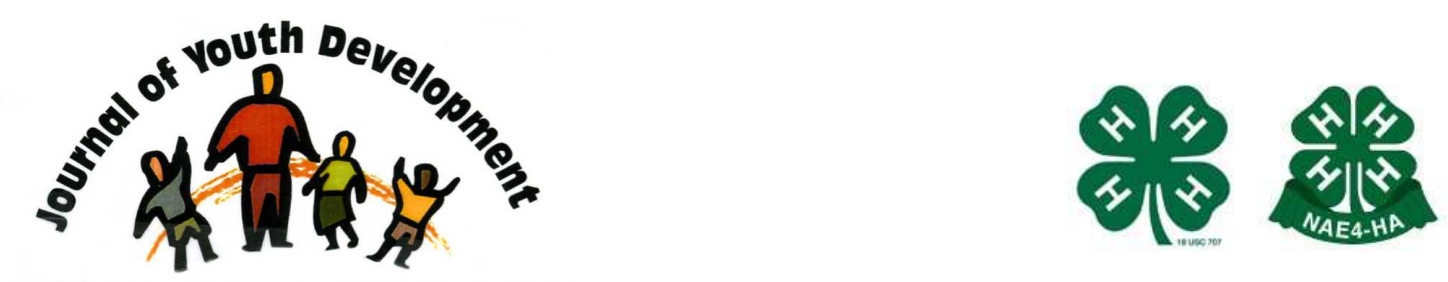

Bridging Research \& Practice

\title{
Parental Limit Setting as a Moderator of Adolescent Paid Work and Alcohol Use
}

\author{
Kelly A. Cheeseman \\ Human Development \& Family Studies \\ University of Delaware \\ Newark, DE \\ kacheeseman7@gmail.com
}

Christine Ohannessian

Human Development \& Family Studies

University of Delaware

Newark, DE 


\title{
JOURNAL OF YOUTH DEVELOPMENT \\ bridging research and practice

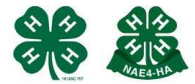

Volume 7, Number 1, Spring 2012

Article 120701FA004

\section{Parental Limit Setting as a Moderator of Adolescent Paid Work and Alcohol Use}

\author{
Kelly A. Cheeseman and Christine Ohannessian \\ University of Delaware
}

\begin{abstract}
Highlighted within this paper is an examination of whether parental limit setting moderates the relationship between paid work and alcohol use during adolescence. The sample included $1,00110^{\text {th }}$ and $11^{\text {th }}$ grade students from public high schools in the Mid-Atlantic region of the United States surveyed in the spring of 2007. Results indicated that parental limit setting significantly moderated the relationships between paid work and frequency of alcohol use for girls and paid work and quantity of alcohol consumption for girls and boys. In general, adolescents who spent less time working and had more parental limits drank the least, whereas adolescents who spent more time working and had less parental limits drank the most. Findings from this study suggest that parental limit setting may protect working adolescents from substance use involvement.
\end{abstract}

\section{Introduction}

Adolescence is a period of biological and psychological developmental challenge (Cicchetti \& Rogosch, 2002; Smetana, Campione-Barr, \& Metzger, 2006). Some of the challenges that adolescents face include puberty, emotional changes, and changes in peer and family relationships (Call, Riedel, Hein, McLoyd, Petersen, \& Kipke, 2002; Smetana et al., 2006). In addition, working for pay for the first time may be an additional challenge, as adolescents attempt to juggle working with school, peer, and family responsibilities (Steinberg \& Dornbusch, 1991).

Historically, adolescence has been viewed as a period of 'storm and stress' (Hall, 1904). Arnett (1999) has identified risk taking behaviors as a central feature of the 'storm and stress' faced by adolescents. Some degree of risk-taking is normative during adolescence (Spear, 2000). One such normative risk-taking behavior is substance use. According to data from the Monitoring the Future Study, in $2008,58 \%$ of $10^{\text {th }}$ graders and $72 \%$ of $12^{\text {th }}$ graders had tried alcohol 
(Johnston, O’Malley, Bachman, \& Schulenberg, 2009). Clearly, many adolescents experiment with alcohol. Alcohol use has been shown to increase during adolescence, peak during late adolescence and early adulthood, and decrease into adulthood (Sher, Grekin, \& Williams, 2005). Importantly, research has shown that adolescent substance use predicts later alcohol abuse and dependence (Conrod, Castellanos, \& Mackie, 2008; Kramer et al., 2008; Pitkanen, Kokko, Lyyra, \& Pulkkinen, 2008).

Working for pay also is a normative event during adolescence. Previous research has found that adolescent paid work may be associated with multiple consequences for adolescents, both positive and negative. Moderate adolescent work (working less than 20 hours per week) has been linked to a reduction in high school dropout (Lee \& Staff, 2007) and has been shown to be beneficial for adolescents during their transition to adulthood by teaching time management and responsibility (Bauermeister, Zimmerman, Barnett, \& Caldwell, 2007). On the other hand, working more than 20 hours per week has been found to be associated with a number of negative consequences, including substance use (Dunn, 2005; Longest \& Shanahan, 2007; Wu, Schlenger, \& Galvin, 2003). For example, Apel and colleagues (2006) found that adolescents who worked more than 20 hours per week were more likely to use alcohol and drugs than adolescents who worked less than 20 hours per week. Longest and Shanahan (2007) also found an increase in adolescent alcohol use associated with adolescents working more than 20 hours per week. Results from these studies suggest that the relationship between paid work and adolescent adjustment varies depending on the number of hours worked (Bachman, Safron, Sy, \& Schulenberg, 2003; McMorris \& Uggen, 2000; Mortimer, Finch, Ryu, Shanahan, \& Call, 1996; Steinberg \& Dornbusch, 1991).

There are several possible explanations for the relationship between working (particularly many hours) and substance use during adolescence. One possible explanation relates to coworkers' influence on the adolescent. Consistent with social learning theory which purports that individuals learn through observing, communicating, and interacting with others (Bandura, 1969; Ward \& Gryczynski, 2009), exposure to older workers may influence adolescent substance use as older workers may serve as models for younger workers (Dunn, 2005). In other words, older workers may model substance use in which younger workers then imitate. Another explanation is that working adolescents are more likely to have income that can be used for substance use than nonworking adolescents. Working adolescents also may have more access to substances than nonworking adolescents.

Another explanation is that adolescent entry into paid work results in a deterioration in parenting practices due to less parental supervision (Longest \& Shanahan, 2007). More specifically, research has shown that working adolescents are less likely to be monitored by parents than nonworking adolescents (Shanahan, Elder, Burchinal, \& Conger, 1996; Steinberg \& Dornbusch, 1991). For example, Manning (1990) found that adolescents who were involved in paid work were less likely to have rules enforced at home than adolescents who were not involved in paid work. Pickering and Vazsonyi (2002) conducted a cross-sectional study examining adolescent work status and family characteristics (family process and family time) of 920 high school students. They found that adolescents who worked less than 20 hours per week reported higher levels of maternal control and supervision than adolescents who worked more than 20 hours per week. Pickering and Vazsonyi (2002) suggested that more parental monitoring resulted in adolescents working less than 20 hours per week. In other words, parents may have limited their adolescents' working hours to retain a high level of parental monitoring. 
According to Hetherington (1993), parental monitoring becomes increasingly critical as children enter adolescence because they spend less time under the direct supervision of parents or other adults and spend more time with peers. Importantly, lower levels of parental monitoring during adolescence have been found to be related to more adolescent externalizing behaviors (Kim, Hetherington, \& Reiss, 1999). Furthermore, limited monitoring knowledge has been found to be associated with greater adolescent risk (Cottrell et al., 2007; Rai et al., 2003; Stanton, Li, \& Pack, 2002; Yang, Stanton, \& Cottrell, et al. 2006), including alcohol and substance use (Stattin \& Kerr, 2000) and delinquent behavior during adolescence (Pettit, Laird, Dodge, Bates, \& Criss, 2001). The benefits of parental monitoring appear to persist throughout adolescence. In a sixwave longitudinal study examining 13-16 year-old adolescents, Barnes, Reifman, Farrell, and Dintcheff (2000) found that high parental monitoring was associated with low initial levels of adolescent alcohol misuse. In addition, high parental monitoring was related to a lower increase of alcohol use throughout adolescence. Kosterman and colleagues (2000) suggested that having good family management (part of which is parental monitoring) can inhibit adolescents from initiating substance use. Many studies also have demonstrated the protective effects of parental monitoring on delinquency. For example, Laird, Pettit, Bates, and Dodge (2003) conducted a study examining the effects of parental monitoring on adolescents' delinquent behavior and found that parental knowledge, as measured by adolescent reports, inhibited adolescents' future involvement in delinquent behavior. In other words, when parents were knowledgeable about their adolescents' activities, adolescents engaged in less delinquent behavior.

It is important to consider adolescent paid work, substance use, and parental monitoring separately for boys and girls. Although gender has not been systematically linked to adolescent paid work (Barnes, Hoffman, Welte, Farrell, \& Dintcheff, 2007; Hilbrecht, Zuzanek, \& Mannell, 2008), gender differences in substance use and parental monitoring have been observed. During adolescence, alcohol is the substance most experimented with and used by both boys and girls (Palmer et al., 2009). In addition, Palmer and colleagues (2009) reported similar levels of substance involvement, including alcohol, tobacco, and marijuana, for boys and girls during Wave 1 of their study, when the adolescents were 11-18 years of age. However, by Wave 2, when the adolescents were 16-25 years of age, a gender difference appeared such that more boys were using substances than girls. Other studies also have found boys to drink alcohol more frequently and more heavily than girls (Keyes, Grant, \& Hasin, 2008; NolenHoeksema \& Hilt, 2006; Patock-Peckham, Cheong, Balhorn, \& Nagoshi, 2001). Consistent with gender differences in alcohol consumption, Johnston et al. (2009) found that boys use illicit drugs more frequently than girls. These results indicate that while both boys and girls experiment with substances during adolescence, boys tend to have a greater involvement with substances in comparison to girls.

Gender differences also have been found for parental monitoring. In general, mothers report higher levels of parental monitoring for girls than for boys (Cottrell et al., 2007). In addition, Wu and colleagues (2004) found that girls have more limits set by their parents than do boys. Taken together, these findings suggest that girls are more closely monitored and have more limits placed on them in comparison to boys.

As discussed above, parental monitoring has been found to be related to the substance use of adolescents. While distinctly different than parental monitoring, parental limit setting is also related to adolescent substance use. Parental monitoring has been defined as parental knowledge about the whereabouts of their children, who they are with, and what they are doing (Laird et al., 2003). On the other hand, parental limit setting has been conceptualized in 
this study as parents setting restrictions on their children and limiting their activities. Less research has been conducted on parental limit setting and its effects on adolescent substance use.

In sum, the present study was designed to extend the literature by exploring whether parental limit setting moderates the relationship between adolescent paid work and alcohol use. Although previous research has suggested links among these variables, this study explicitly examined the relationships among parental limit setting, adolescent paid work, and adolescent alcohol use while addressing some of the limitations of previous research. Prior work in this area has been limited by the examination of small samples (Brody, Ge, Katz, \& Arias, 2000; Furman, Simon, Shaffer, \& Bouchey, 2002; Pettit et al., 2001) and homogenous samples (e.g., not racially diverse) (Barnes, Hoffman, Welte, Farrell, \& Dintcheff, 2006; Kim, Hetherington, \& Reiss, 1999; Kosterman et al., 2000). In addition, some studies (e.g., Kosterman et al., 2000) have examined preadolescents or children (e.g., elementary school students) who are less likely to engage in substance use than adolescents. Many studies also have not taken the gender of the adolescent into account. Given these limitations, the present study examined a large, diverse sample of adolescents to address the following research questions:

1) Is paid work associated with alcohol use during adolescence?

2) Is parental limit setting related to alcohol use during adolescence?

3) Does parental limit setting moderate the relationship between adolescent paid work and alcohol use? and

4) Do these relationships differ by the gender of the adolescent?

\section{Method}

\section{Participants}

All of the participants were involved in a larger research project (The Adolescent Adjustment Project; Ohannessian, 2009) which began in 2006. The present study was based on data collected during the spring of 2007 . The sample included $1,00110^{\text {th }}(58 \%)$ and $11^{\text {th }}$ grade students from seven public high schools in the Mid-Atlantic region of the United States. Approximately one half of the adolescents (53\%) were girls. The age of the students ranged from 15 to 17 years old, with a mean of $16.09(S D=0.68)$. The majority of the adolescents (59\%) were Caucasian; 22\% were African-American, $12 \%$ were Hispanic, and $2 \%$ were Asian (the remainder chose "other" to describe their race/ethnicity). Most of the adolescents reported that they lived with both of their biological parents (56\%). Specifically, 89\% reported that they lived with their biological mother, $61 \%$ with their biological father, $15 \%$ with a step-father, $4 \%$ with a stepmother, $2 \%$ with an adoptive mother, or $1 \%$ with an adoptive father. The majority of the adolescents' parents had completed high school ( $96 \%$ of mothers and $95 \%$ of fathers). In addition, some of the adolescents' parents had completed four years of college ( $26 \%$ of mothers and $24 \%$ of fathers) and a minority had attended graduate school ( $10 \%$ of mothers and $7 \%$ of fathers).

\section{Measures}

Paid work. All of the adolescents were asked to complete a measure assessing their participation in extracurricular activities. This measure consists of eleven items that reflect the frequency of participation in extracurricular activities, including one item regarding paid work. Adolescents were asked to rate their frequency of participation. Because there was a relative lack of variation in the distribution, responses were collapsed into the following four categories: no involvement, once a week or less, 2-3 days per week, or 3 days per week or more. 
Alcohol use. Adolescents also were asked to complete an alcohol use survey. Specifically, the adolescents were asked to report their frequency of alcohol consumption by responding to the question "How often did you usually have a beer/wine/liquor in the last 6 months?" The response scale was an eight-point scale ranging from never to every day. A composite score was created for frequency of alcohol use by summing the responses for beer, wine, and liquor to reflect total frequency of alcohol consumption. This composite score ranged from 0-21.

In addition to reporting their frequency of alcohol use, adolescents were asked to report their quantity of alcohol consumption by indicating how many cans of beer, glasses of wine, or drinks of liquor they had drank in the past six months. Specifically, they were asked "When you had beer/wine/liquor, on the average day, how much did you usually drink in the last 6 months?" A composite score was created for quantity of alcohol consumption by adding the responses for beer, wine, and liquor. Because this score was skewed, it was linearly transformed.

Parental limit-setting. The Parental-Limit Setting Measure (PLSM; Turner, Irwin, \& Millstein, 1991) was given to adolescents in order to assess parental discipline style and monitoring. This measure is a 16-item self-report measure which asks respondents to indicate whether or not parents/guardians allow them to do specific activities. Examples of included activities are staying out with friends until midnight, sleeping over a friend's house, and riding in a car with friends. The items from the PLSM are summed to create a total score. The score ranges from $0-16$, with a lower score indicating more parental limits. In the present sample, the Cronbach alpha coefficient for the PLSM was .78.

\section{Procedure}

Students in $10^{\text {th }}$ and $11^{\text {th }}$ grade attending one of seven public high schools in the Mid-Atlantic region of the U.S. were invited to participate in this study. Between March and May of 2007, students for whom parental consent was obtained, and who provided their own assent, were administered a self-report survey at school by trained research staff (all of whom were certified with human services training). Of the possible 1,462 students who were invited to participate in the study, 1,033 students provided their assent to participate (70.6\% participation rate). From the 1,033 students who provided their assent, 1,001 15-17 years-olds completed the survey. Upon giving their assent, the research staff reassured the adolescents that their information was confidential, that participation in the project was voluntary, and that they could withdraw their participation from the study at any time. The protocol for this study was approved by the University of Delaware's Institutional Review Board. To further protect the privacy of the adolescents, an active Certificate of Confidentiality from the U.S. Government was in place for this project. The survey took approximately 40 minutes to complete. Upon completion of the survey packet, adolescents received a free movie pass for participating in the study.

\section{Results}

Bivariate relations. Correlations between all of the study variables are presented in Table 1. As shown, all of the variables were significantly correlated with one another $(p<.01)$. In addition, the correlations were similar for boys and girls. Paid work was related to both the frequency and quantity of alcohol use for boys and for girls, indicating that adolescents who worked more used alcohol more than adolescents who worked less. In addition, parental limit setting was related to both the frequency and quantity of alcohol use for boys and for girls, with more parental limits associated with less alcohol use. 
Table 1

Paid Work, Frequency of Alcohol Use, Quantity of Alcohol Use, and Parental Limit Setting: Correlations

\begin{tabular}{|l|c|c|c|c|}
\hline Variables & $\mathbf{1}$ & $\mathbf{2}$ & $\mathbf{3}$ & $\mathbf{4}$ \\
\hline 1. Paid Work & - & $.22^{* *}$ & $.21^{* *}$ & $.17^{* *}$ \\
2. Frequency of Alcohol Use & $.18^{* *}$ & - & $.73^{* *}$ & $.16^{* *}$ \\
3. Quantity of Alcohol Use & $.12^{* *}$ & $.79 * *$ & - & $.17^{* *}$ \\
4. Parental Limit Setting & $.25^{* *}$ & $.25^{* *}$ & $.22^{* *}$ & - \\
\hline
\end{tabular}

$* * p<.01$.

\section{Analysis of variance models.}

Gender differences, An Analysis of Variance (ANOVA) model was conducted to examine whether there were gender differences in parental limit setting and alcohol use. The overall models for parental limit setting and alcohol use were not significant. These results suggest that parental limit setting and alcohol use were similar for boys and girl.

A series of Analysis of Variance (ANOVA) models was conducted to examine whether paid work is related to alcohol use, whether parental limit setting is related to alcohol use, and whether parental limit setting moderates the relationship between paid work and alcohol use. Prior to conducting these analyses, the parental limit setting variable was dichotomized using a median split. Separate models were run for the frequency of alcohol use and the average quantity of alcohol consumed, by gender.

Frequency of alcohol use. The overall model for frequency of alcohol use for boys was significant $\{F(7,379)=5.89, p<.001\}$. In addition, a significant main effect was found for paid work $\{F(3,379)=8.23, p<.001\}$, indicating that boys who worked more drank more frequently than boys who worked less. A significant main effect also was observed for parental limit setting $\{F(1,379)=10.32, p<.001\}$, suggesting that boys who had fewer parental limits drank more frequently than boys who had more parental limits. The interaction between paid work and parental limit setting was not significant for boys.

For girls, the overall model for frequency of alcohol use was significant $\{F(7,451)=5.87, p<$ $.001\}$. The main effect for paid work was not significant; however, a significant main effect for parental limit setting was observed $\{F(1,451)=7.01, p<.01\}$, indicating that girls who had less parental limits drank more frequently than girls who had more parental limits. In addition, a significant interaction was found between paid work and parental limit setting for girls $\{F(3$, $451)=3.66, p<.05\}$, suggesting that girls who spent more time working and had fewer parental limits drank the most frequently, whereas girls who spent less time working and had more parental limits drank the least frequently (see Figure 1). 
Figure 1

Frequency of Alcohol Use and Paid Work for Girls

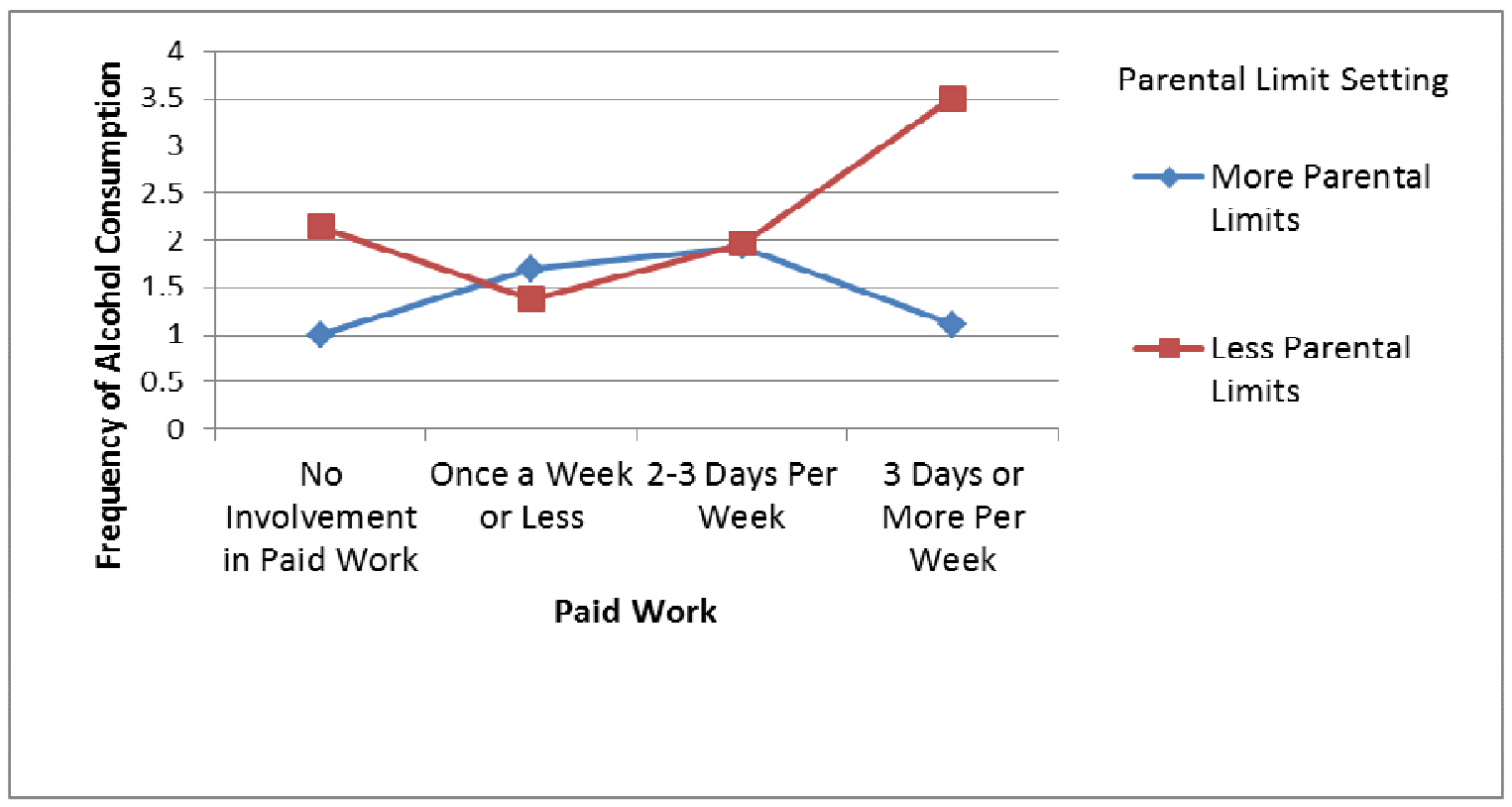

Quantity of alcohol consumption. The overall model for quantity of alcohol use was significant for boys $\{F(7,364)=7.20, p<.001\}$. A significant main effect was found for paid work $\{F(3,364)=9.36, p<.001\}$, indicating that boys who worked more consumed more alcohol than boys who worked less. A significant main effect also was found for parental limit setting $\{F(1,364)=8.24, p<.01\}$, suggesting that boys who had fewer parental limits consumed more alcohol than boys who had more parental limits. In addition, there was a significant interaction between paid work and parental limit setting for boys $\{F(3,364)=2.65$, $p<.05\}$, indicating that boys who worked more and had fewer parental limits drank the most, whereas boys who worked less and had more parental limits drank the least (see Figure 2).

Figure 2

Quantity of Alcohol Use and Paid Work for Boys

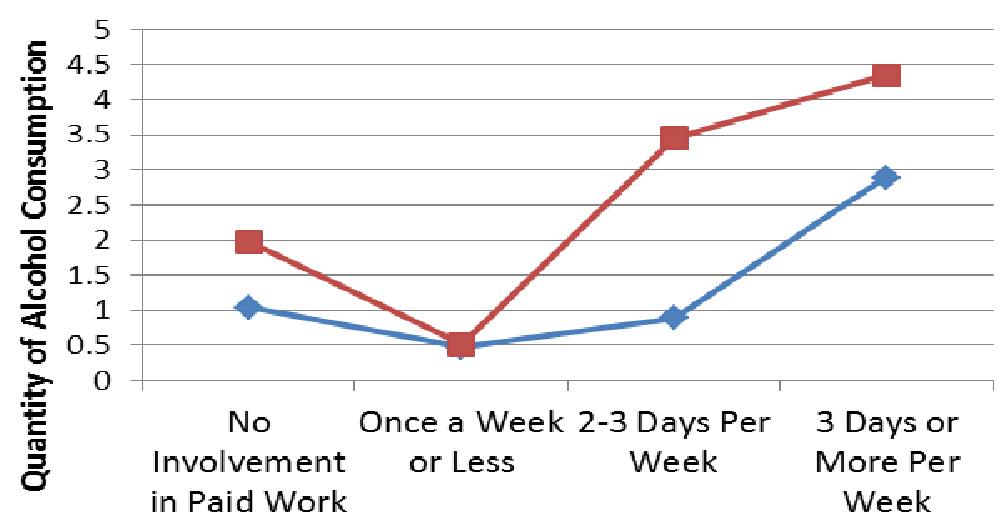

Parental Limit Setting

- More Parental Limits

- Less Parental Limits

Paid Work 
For girls, the overall model for quantity of alcohol use was significant $\{F(7,423)=6.92, p<$ $.001\}$. The main effect for paid work was not significant; however, there was a significant main effect for parental limit setting $\{F(1,423)=8.57, p<.01\}$, indicating that girls who had fewer parental limits consumed more alcohol than girls who had more parental limits. In addition, a significant interaction was found between paid work and parental limit setting for girls $\{F(3$, $423)=4.88, p<.01\}$. Similar to boys, this interaction suggested that girls who worked more and had fewer parental limits drank the most, whereas girls who worked less and had more parental limits drank the least (see Figure 3).

Figure 3

Quantity of Alcohol Use and Paid Work for Girls

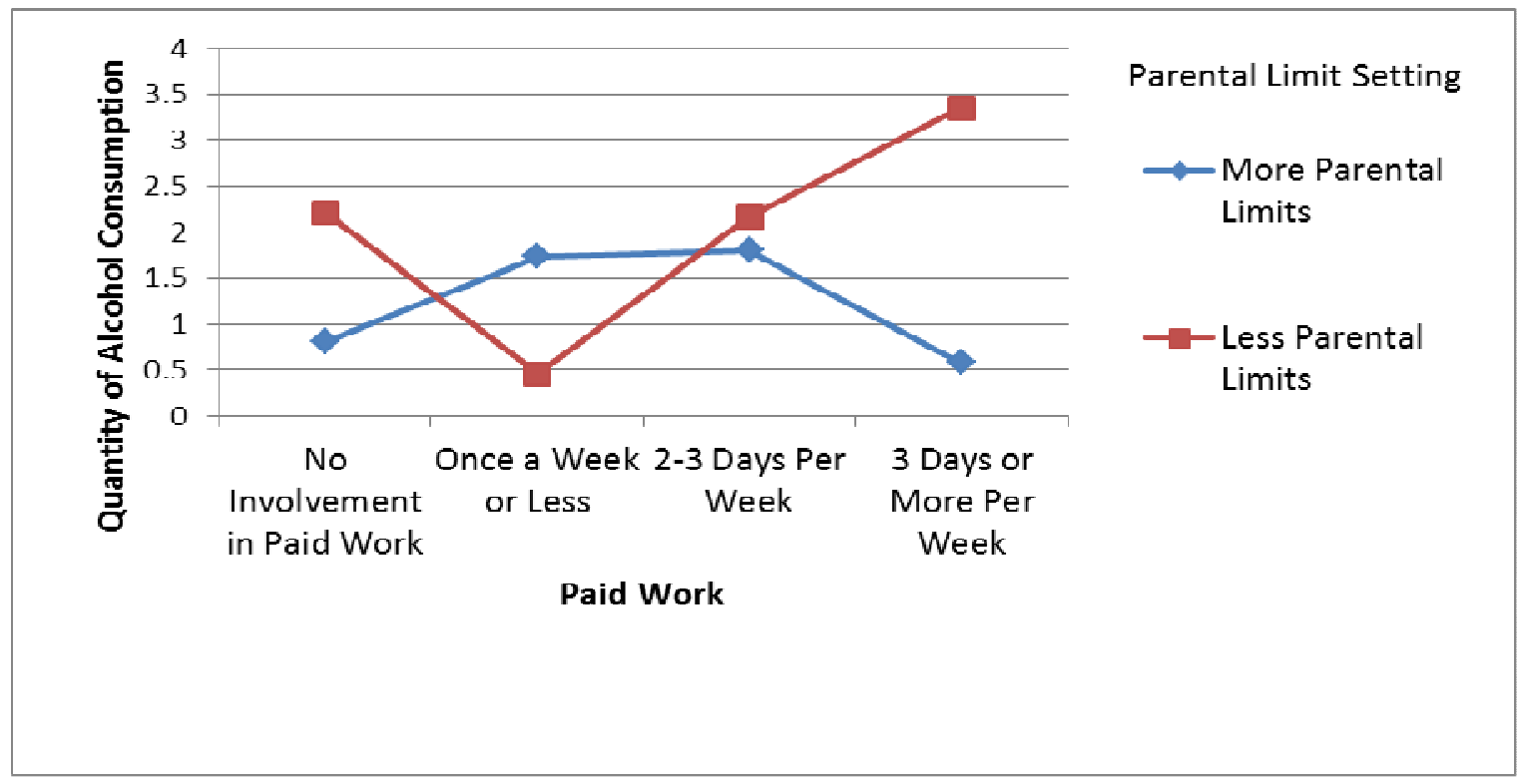

\section{Discussion}

In general, the results from this study are consistent with previous research. A primary aim of this study was to examine whether paid work is related to alcohol use during adolescence. Consistent with previous research (Dunn, 2005; Longest \& Shanahan, 2007; Wu, et al., 2003), the results indicate that high levels of paid work are associated with high levels of alcohol consumption. It should be noted that most of the previous research on this topic (Apel et al., 2006; Bachman et al., 2003; Longest \& Shanahan, 2007; McMorris \& Uggen, 2000) has used the number of hours worked per week as the measure of adolescent paid work. In contrast, the metric used in the present study was the number of days worked per week. Nonetheless, results from this study are consistent with prior studies. For instance, Apel and colleagues (2006) found that adolescents who worked more than 20 hours per week were more likely to use substances in comparison to adolescents who worked less than 20 hours per week. Consistent with Apel et al.'s findings, in the present study, adolescents who worked more than 3 days per week were more likely to use substances than adolescents who worked less than 3 days per week. While direct comparison among studies cannot be made because of the difference in measurement, our findings add to the body of research in this area by considering another method of measuring adolescent paid work. 
Consistent with previous research on parental monitoring (Barnes et al., 2000; Kim, Hetherington, \& Reiss, 1999), the results from this study indicate that parental limit setting is associated with adolescent alcohol use. Previous research has found that parents who have less knowledge about their adolescents' whereabouts tend to have adolescents who engage in substance use (Stattin \& Kerr, 2000). Similarly, in the present study, adolescents who had parents that set more limits tended to have lower alcohol consumption (frequency and quantity) than adolescents who had parents that set fewer limits on their adolescent. Although different measures of parenting were used in these studies, these studies indicate that parental supervision (especially monitoring and limit setting) may decrease an individual's involvement with alcohol during adolescence.

Of note, gender differences in parental limit setting and alcohol use were not observed in this study indicating that boys and girls had similar levels of parental limit setting and alcohol use. These findings are not consistent with previous research. Prior studies have found that boys tend to use alcohol more than girls during adolescence (Keyes, et al., 2008; Nolen-Hoeksema \& Hilt, 2006; Patock-Peckham et al., 2001). Similar to the present study, Palmer and colleagues (2009) found no gender difference at Wave 1 when their sample was 11-18 years old, but a gender difference was found at Wave 2 when the youth were 16-25 years old. At Wave 2, boys had a higher rate of substance use than girls. The age of the present sample was similar to Palmer and colleague's sample at Wave 1 . Therefore, the absence of gender differences in alcohol use may be related to the age of the adolescents. It would be informative to examine alcohol use in these adolescents as they progress through adolescence to explore when gender differences in alcohol use emerge.

As noted above, there were no gender differences in parental limit setting observed in this study. These results are in contrast to previous research that has found gender differences in parental limits (Wu et al., 2004) and in parental monitoring, a similar but slightly different construct (Cottrell et al., 2007). In the Wu et al. study, more limits were set for girls in comparison to boys. Similarly, in the Cottrell et al. study, girls were found to be more closely monitored by their parents than were boys. It should be noted that Cottrell and colleagues (2007) examined parental monitoring from a maternal perspective, whereas the present study examined parental limit setting from the adolescent's perspective. The difference in respondent could explain the differential results. In addition, the age of the participants differed across the studies. For example, Cottrell et al. examined a sample of 9-13 year-olds, whereas the present study examined 15-17 year-olds. Perhaps parents are more protective of younger adolescents, particularly girls, than they are of older adolescents. It also should be noted that while the measure used by Wu and colleagues (2004) assessed the same construct assessed in the present study, parental limit setting, the sample Wu and colleagues (2004) examined was a clinical sample of adolescents who were receiving treatment for substance use. Perhaps parents of youth experiencing problems are extra protective, especially if they are girls. Future research should address these possibilities.

In sum, the present study makes an important contribution to the literature because the moderating effect of parental limit setting on the relationship between paid work and alcohol use during adolescence was examined. Because adolescent paid work has been shown to be associated with an increase in the use of alcohol and drugs (Dunn, 2005; Longest \& Shanahan, 2007; Wu et al., 2003), it is important to help families identify ways to buffer this negative consequence. In the present study, parental limit setting did not moderate the relationship between adolescent paid work and frequency of alcohol use for boys; however, it did for girls. More specifically, for girls, parental limit setting buffered the effects of paid work on the 
frequency of alcohol use. For quantity of alcohol use, parental limit setting moderated the relationship between adolescent paid work and the quantity of alcohol use for both boys and girls, suggesting that parental limit setting may protect working adolescents from involvement with alcohol.

Although this study extends the current literature, a few caveats of the study should be noted. The present study relied on self-report measures. Therefore, the results should be validated using other forms of methodologies, such as parental reports. In addition, caution should be taken in regard to generalizing the findings of this study because the sample only included $10^{\text {th }}$ and $11^{\text {th }}$ grade students living in the Mid-Atlantic United States. Also, causal relations should not be inferred due to the cross-sectional design.

In light of these limitations, the present study makes an important contribution to the literature because the moderating effect of parental limit setting on the relationship between paid work and alcohol use was examined in a large, diverse sample of adolescents. In addition, gender differences were taken into account. Importantly, the results from this study have implications for the prevention of adolescent substance use. Although results from this study indicate that working many hours per week may be deleterious during adolescence, previous research has indicated that paid work may have positive effects, such as a reduction in high school dropout (Lee \& Staff, 2007) and teaching time management and responsibility (Bauermeister et al., 2007). Therefore, it is not advisable to suggest that adolescents not engage in paid work. However, results from this study suggest that working during adolescence may be beneficial, given that work hours are not excessive and parental limits are in place (e.g., parents closely monitoring their adolescent's activities). Based on the findings from this study, substance use prevention programs should consider including parent education (e.g., discussing the importance of parental limit setting and parental monitoring) as a primary component. If parents are educated about the protective effects of parental limit setting, they may be more likely to set firm limits and monitor their adolescent's activities, and subsequently decrease their adolescent's use of alcohol.

\section{References}

Apel, R., Paternoster, R., Bushway, S.D., \& Brame, R. (2006). A job isn't just a job: The differential impact of formal versus informal work on adolescent problem behavior. Crime $\&$ Delinquency, 52, 333-369.

Arnett, J.J. (1999). Adolescent storm and stress, reconsidered. American Psychologist, 54, 317326.

Bachman, J.G., Safron, D.J., Sy, S.R., \& Schulenberg, J.E. (2003). Wishing to work: New perspectives on how adolescents' part-time work intensity is linked to educational disengagement, substance use, and other problem behaviours. International Journal of Behavioral Development, 27, 301-315.

Bandura, A. (1969). Principles of behavior modification. New York: Rinehart and Winston.

Barnes, G.M., Hoffman, J.H., Welte, J.W., Farrell, M.P., \& Dintcheff, B.A. (2007). Adolescents' time use: Effects on substance use, delinquency and sexual activity. Journal of Youth and Adolescence, 36, 697-710. 
Barnes, G.M., Hoffman, J.H., Welte, J.W., Farrell, M.P., \& Dintcheff, B.A. (2006). Effects of parental monitoring and peer deviance on substance use and delinquency. Journal of Marriage and Family, 68, 1084-1104.

Barnes, G.M., Reifman, A.S., Farrell, M.P., \& Dintcheff, B.A. (2000). The effects of parenting on the development of adolescent alcohol misuse: A six-wave latent growth model. Journal of Marriage and the Family, 62, 175-186.

Bauermeister, J.A., Zimmerman, M.A., Barnett, T.E., \& Caldwell, C.H. (2007). Working in high school and adaptation in the transition to young adulthood among African American youth. Journal of Youth and Adolescence, 36, 877-890.

Brody, G.H., Ge, X., Katz, J., \& Arias, I. (2000). A longitudinal analysis of internalization of parental alcohol-use norms and adolescent alcohol use. Applied Developmental Science, 4, 7179.

Call, K.T., Riedel, A.A., Hein, K., Mcloyd, V., Petersen, A., \& Kipke, M. (2002). Adolescent health and well-being in the twenty-first century: A global perspective. Journal of Research on Adolescence, 12, 69-98.

Cicchetti, D., \& Rogosch, F.A. (2002). A developmental psychopathology perspective on adolescence. Journal of Consulting and Clinical Psychology, 70, 6-20.

Conrod, P.J., Castellanos, N., \& Mackie, C. (2008). Personality-targeted interventions delay the growth of adolescent drinking and binge drinking. Journal of Child Psychology and Psychiatry, 49, 181-190.

Cottrell, L., Yu, S., Liu, H., Deveaux, L., Lunn, S., Bain, R.M., \& Stanton, B. (2007). Genderbased model comparisons of maternal values, monitoring, communication, and early adolescent risk behavior. Journal of Adolescent Health, 41, 371-379.

Dunn, M.S. (2005). The relationship between religiosity, employment, and political beliefs on substance use among high school seniors. Journal of Alcohol and Drug Education, 49, 73-88.

Furman, W., Simon, V.A., Shaffer, L., \& Bouchey, H.A. (2002). Adolescents' working models and styles for relationships with parents, friends, and romantic partners. Child Development, 73, 241-255.

Hall, G.S. (1904). Adolescence: Its psychology and its relation to physiology, anthropology, sociology, sex, crime, religion, and education (Vols. I \& II). Englewood Cliffs, NJ: Prentice-Hall.

Hetherington, E.M. (1993). An overview of the Virginia longitudinal study of divorce and remarriage with a focus on early adolescence. Journal of Family Psychology, 7, 39-56.

Hilbrecht, M., Zuzanek, J., \& Mannell, R.C. (2008). Time use, time pressure and gendered behavior in early and late adolescence. Sex Roles, 58, 342-357.

Johnston, L.D., O'Malley, P.M., Bachman, J.G., \& Schulenberg, J.E. (2009). Monitoring the Future national results on adolescent drug use: Overview of key findings, 2008 (NIH Publication No. 09-7401). Bethesda, MD: National Institute on Drug Abuse, 73 pp. 
Keyes, K.M., Grant, B.F., \& Hasin, D.S. (2008). Evidence for a closing gender gap in alcohol use, abuse, and dependence in the United States population. Drug and Alcohol Dependence, 93, 2129.

Kim, J.E., Hetherington, E.M., \& Reiss, D. (1999). Associations among family relationships, antisocial peers, and adolescents' externalizing behaviors: Gender and family type differences. Child Development, 70, 1209-1230.

Kosterman, R., Hawkins, J., Guo, J., Catalano, R.F., \& Abbott, R.D. (2000). The dynamics of alcohol and marijuana initiation: Patterns and predictors of first use in adolescence. American Journal of Public Health, 90, 360-366.

Kramer, J.R., Chan, G., Dick, D.M., Kuperman, S., Bucholz, K.K., Edenberg, H.J., et al. (2008). Multiple-domain predictors of problematic alcohol use in young adulthood. Journal of Studies on Alcohol and Drugs, 69, 649-659.

Laird, R.D., Pettit, G.S., Bates, J.E., \& Dodge, K.A. (2003). Parents' monitoring-relevant knowledge and adolescents' delinquent behavior: Evidence of correlated developmental changes and reciprocal influences. Child Development, 74, 752-768.

Lee, J.C., \& Staff, J. (2007). When work matters: The varying impact of work intensity on high school dropout. Sociology of Education, 80, 158-178.

Longest, K.C., \& Shanahan, M.J. (2007). Adolescent work intensity and substance use: The mediational and moderational roles of parenting. Journal of Marriage and Family, 69, 703-720.

Manning, W.D. (1990). Parenting employed teenagers. Youth \& Society. Special Issue: Youth and Work, 22, 184-200.

McMorris, B.J. \& Uggen, C. (2000). Alcohol employment in the transition to adulthood. Journal of Health Social Behavior, 41, 276-294.

Mortimer, J.T., Finch, M.D., Ryu, S., Shanahan, M.J., \& Call, K.T. (1996). The effect of work intensity on adolescent mental health, achievement, and behavioral adjustment: New evidence from a prospective study. Child Development, 67, 1243-1261.

Nolen-Hoeksema, S., \& Hilt, L. (2006). Possible contributors to the gender differences in alcohol use and problems. Journal of General Psychology, 133, 357-374.

Ohannessian, C.M. (2009). Media use and adolescent psychological adjustment: An examination of gender differences. Journal of Child and Family Studies, 18, 582-593.

Palmer, R.H., Young, S.E., Hopfer, C.J., Corley, R.P., Stallings, M.C., Crowley, T.J., \& Hewitt, J.K. (2009). Developmental epidemiology of drug use and abuse in adolescence and young adulthood: Evidence of generalized risk. Drug and Alcohol Dependence, 102, 78-87.

Patock-Peckham, J.A., Cheong, J., Balhorn, M.E., \& Nagoshi, C.T. (2001). A social learning perspective: A model of parenting styles, self-regulation, perceived drinking control, and alcohol use and problems. Alcoholism: Clinical and Experimental Research, 25, 12841292. 
Pettit, G.S., Laird, R.D., Dodge, K.A., Bates, J.E., \& Criss, M.M. (2001). Antecedents and behavior-problem outcomes of parental monitoring and psychological control in early adolescence. Child Development, 72, 583-598.

Pickering, L.E., \& Vazsonyi, A.T. (2002). The impact of adolescent employment on family relationships. Journal of Adolescent Research, 17, 196-218.

Pitkanen, T., Kokko, K., Lyyra, A.L., \& Pulkkenen, L. (2008). A developmental approach to alcohol drinking behaviour in adulthood: A follow-up study from age 8 to age 42. Addiction, $103,48-68$.

Rai, A.A., Stanton, B., Wu, Y., Li, X., Galbraith, J., Cottrell, L., et al. (2003). Relative influences of perceived parental monitoring and perceived peer involvement on adolescent risk behaviors: An analysis of six cross-sectional data sets. Journal of Adolescent Health, 33, 108-118.

Shanahan, M.J., Elder, G.H., Jr., Burchinal, M., \& Conger, R.D. (1996). Adolescent paid labor and relationships with parents: Early work-family linkages. Child Development, 67, 2183-2200.

Sher, K.J., Grekin, E.R., \& Williams, N.A. (2005). The development of alcohol use disorders. Annual Review of Clinical Psychology, 1, 493-523.

Smetana, J.G., Campione-Barr, N., \& Metzger, A. (2006). Adolescent development in interpersonal and societal contexts. Annual Review of Psychology, 57, 255-284.

Spear, L.P. (2000). The adolescent brain and age-related behavioral manifestations. Neuroscience and Biobehavioral Reviews, 24, 417-463.

Stanton, B., Li, X., \& Pack, R. (2002). Longitudinal influence of perceptions of peer and parental factors on African American adolescent risk involvement. Journal of Urban Health, 79, 536-548.

Stattin, H., \& Kerr, M. (2000). Parental monitoring: A reinterpretation. Child Development, 71, 1072-1085.

Steinberg, L., \& Dornbusch, S.M. (1991). Negative correlates of part-time employment during adolescence: Replication and elaboration. Developmental Psychology, 27, 304-313.

Turner, R.A., Irwin, C.E., \& Millstein, S.G. (1991). Family structure, family process, and experimenting with substances during adolescence. Journal of Research on Adolescence, 1, 93106.

Ward, B.W. \& Gryczynski, J. (2009). Social learning theory and the effects of living arrangement on heavy alcohol use: Results from a national study of college students. Journal of Studies on Alcohol and Drugs. Special Issue: Ethnicity and adolescent pathways to alcohol use, 70, 364-372.

Wu, N.S., Lu, Y., Sterling, S., \& Weisner, C. (2004). Family environment factors and substance abuse severity in an HMO adolescent treatment population. Clinical Pediatrics, 43, 323-333. 
Wu, L., Schlenger, W.E., \& Galvin, D.M. (2003). The relationship between employment and substance use among students aged 12 to 17. Journal of Adolescent Health, 32, 5-15.

Yang, H., Stanton, B., Cottrell, L., Kaljee, L., Galbraith, J., Li, X., et al. (2006). Parental awareness of adolescent risk involvement: Implications of overestimates and underestimates. Journal of Adolescent Health, 39, 353-361.

(C) Copyright of Journal of Youth Development Bridging Research and Practice. Content may not be copied or emailed to multiple sites or posted to a listserv without copyright holder's express written permission. However, users may print, download or email articles for individual use. 